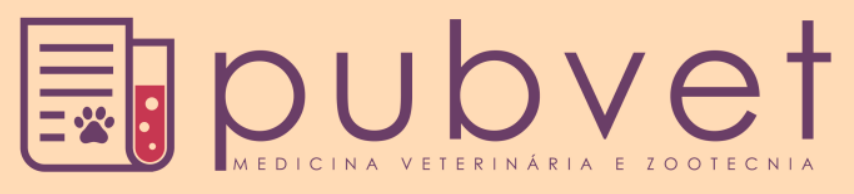

https://doi.org/10.22256/pubvet.v12n7a130.1-5

\title{
A reutilização de um implante de Norgestomet na manifestação de estro ovino
}

\author{
José Francisco Manta Bragança ${ }^{\bullet}$ 1* $^{*}$ Ricardo Xavier da Rocha ${ }^{\bullet} 2$ \\ ${ }^{I}$ Professor da Universidade do Oeste de Santa Catarina. Xanxerê. Brasil. *Autor para correspondência. E-mail: jose.braganca@unoesc.edu.br \\ ${ }^{2}$ Médico Veterinário Autônomo. RR serviços em Medicina de Ruminantes Carazinho. Brasil. E-mail: ricardorocha.vet@gmail.com
}

RESUMO. Este estudo experimental avaliou a reutilização de um implante auricular de Norgestomet na manifestação de estro ovino. Para tanto, foram empregadas 60 borregas da raça Texel as quais, após terem sua condição corporal (CC3-4) e peso vivo (50 a $60 \mathrm{Kg}$ ) avaliados foram separadas ao acaso em dois grupos: o grupo NorgN $(n=30)$, controle e o grupo NorgR $(n=30)$ experimental. Previamente ao início do trabalho 30 dispositivos auriculares foram utilizados em bovinos para sincronizar o seus estros e assim, serem obtidos os dispositivos para uso no grupo NorgR (reutilizado). As doses de Norgestomet empregadas nos grupos foi $1 / 3$ da recomendada para a espécie bovina. O protocolo hormonal empregado nos grupos consistiu na aplicação de um dispositivo auricular no dia 0 (início do experimento) por seis dias. Na retirada do dispositivo (dia 6) foram aplicados pela via intramuscular um análogo de prostaglandina $(1 \mathrm{ml})$ e eCG (400 UI) sendo disponibilizadas às fêmeas junto aos reprodutores com seu peitoral pintado para detectar os estros por 5 dias após, a retirada do dispositivo. As fêmeas do grupo NorgR receberam os dispositivos reutilizados previamente. Em relação à manifestação de estros nos grupos um total de 95\% (57/60) das fêmeas o manifestaram. Em relação à distribuição da manifestação $100 \%$ (30/30) e 90\% (27/30) das fêmeas dos grupos NorgN e NorgR respectivamente o manifestaram em um período de $36 \mathrm{~h}$ após a retirada do dispositivo. Conclui-se que dispositivos auriculares a base de Norgestomet novos e reutilizados quando associado à eCG e a um análogo de prostaglandina permitem uma satisfatória manifestação estral em borregas da raça Texel.

Palavras chaves: Borregas, eCG, prostaglandina, Texel

\section{The reuse of Norgestomet implants on estrus manifestation ovine}

ABSTRACT. This study assessed the efficacy of the re-utilization of a Norgestomet ear implant in the sheep. Following body condition scoring (CC 3-4) and weight (50-60 Kg) evaluation 60 Texel ewe lambs were randomly assigned to two experimental groups: NorgN (new) control group $(n=30)$, and NorgR (re-used) treatment group $(n=30)$. The implants employed in the treatment group were previously used in estrus synchronization of cows. The ewe lambs were treated with $1 / 3$ of the dosage of Norgestomet recommended for cows. The estrus synchronization protocol consisted of administration of an ear implant at day 0 (beginning of experiment) for 6 days. At implant removal (day 6) the animals received i.m. injections of a prostaglandin analogue (xxx mg) and eCG (400 IU). Teaser rams with brisket paint were used to mark the ewes in heat for 5 days after implant withdrawal. In total, 95\% (57/60) of the ewes displayed estrus. 100\% (30/30) and 90\% (27/30) of the ewes in NorgN and NorgR groups, respectively, displayed estrus 36 hours after implant removal. In conclusion, Norgestomet ear implants associated with eCG and a prostaglandin analogue can be successfully reused to synchronize estrus in Texel ewe lambs. 
Keywords: eCG, Ewe lambs, prostaglandin, Texel

\section{La reutilización de un implante de Norgestomet en la manifestación de celo ovino}

RESUMEN. Este estudio evaluó la reutilización de un implante auricular de Norgestomet en la manifestación de celos ovino. Para tanto, fueron empleadas 60 borregas de la raza Texel las cuales después de evaluar su condición corporal (CC3-4) y peso vivo (50-60 Kg) fueron separados al azar en dos grupos: grupo NorgN ( $\mathrm{n}=30)$, control y el grupo NorgR $(\mathrm{n}=30)$ experimental. Previo al comienzo de los trabajos 30 dispositivos auriculares fueron empleados en hembras bovinas para sincronizar sus celos y así, obtenerse los dispositivos para empleo en animales ovinos del grupo NorgR (reutilizado). Las dosis de Norgestomet empleadas en los grupos fueron $1 / 3$ de la recomendada para empleo en bovinos. El protocolo hormonal empleado en los grupos consistió en la aplicación de un dispositivo auricular en el día 0 (inicio del experimento) por seis días. En la retirada del dispositivo (día 6) fueron aplicados por vía intramuscular un análogo de prostaglandina (1ml) y eCG (400UI) siendo colocadas las hembras junto a los reproductores con su pecho pintado para detectar celos por cinco días luego de retirado los dispositivos. Las hembras del grupo NorgR recibieron los dispositivos empleados previamente. En relación a la manifestación de celos en los grupos, un total de 95\% (57/60) de hembras lo manifestaron. En relación a la distribución de la manifestación, 100\% (30/30) y 90\% (27/30) de las hembras de los grupos NorgN y NorgR respectivamente lo manifestaron en un período de $36 \mathrm{~h}$ luego de la retirada del dispositivo. Se concluye que dispositivos auriculares a base de Norgestomet nuevos y reutilizados cuando asociados a la eCG y a un análogo de prostaglandina permiten una satisfactoria manifestación de celos en borregas de la raza Texel.

Palabras clave: Borregas, eCG, prostaglandina, Texel

\section{Introdução}

A ovinocultura é das atividades do agronegócio que mais cresceu nos últimos anos. Uma das causas principais é a valorização da carne ovina no mercado mundial e nacional. Para tanto, a necessidade de o Brasil suprir o seu mercado interno o qual, se encontra em elevação, depende de carne importada, principalmente do Uruguai o que exige um maior estímulo ao aumento da produção interna.

Pensando nisso, uma das alternativas é melhorar o manejo reprodutivo dos rebanhos e assim, a aplicação de biotécnicas reprodutivas tipo, indução e sincronização de estros surgem como ferramentas de opção tanto as naturais (efeito macho) como as farmacológicas (protocolos hormonais). A sincronização e ou indução de estros consiste em manipular o ciclo estral permitindo a redução do mesmo. Ainda, o encurtamento da estação de nascimentos permite o planejamento dos partos e a formação de lotes uniformes de cordeiros (Godfrey et al., 1999). Essas vantagens possibilitam ao produtor aproveitar as condições melhores de demanda de mercado como também, com o ordenamento da estação reprodutiva aproveitar o melhor momento da disponibilidade de forragens (Henderson et al., 1984; Farfán et al., 2004).

Nesse sentido, a progesterona surgiu como o primeiro hormônio utilizado para a sincronização de estros nas espécies. É empregada na forma de dispositivos intravaginais, via oral e ainda, intramuscular e auricular (Gonçalves et al., 2002; Knights et al., 2001). Nesta última forma de emprego, o Norgestomet (implantes) é usado na sincronização de estros e melhora da fertilidade de vacas sub-férteis como também, em ovinos (Woody et al., 1983) podendo ser empregado em ovelhas tanto na estação reprodutiva como fora dela (Hayatu et al., 2009).

Outra opção na sincronização de estro ovino consiste na associação aos progestágenos de gonadotrofinas tipo eCG. Esta gonadotrofina quando associada ao progestágeno estimula a atividade reprodutiva em ovelhas no anestro estacional (Dutt, 1952) aumentando a incidência de estro e ovulação como a taxa ovulatória (Killen \& Moore, 1970; Nagvi et al., 1996). Esse aumento de taxa ovulatória é por permitir o recrutamento de folículos ovarianos menores, pelo aumento da taxa de crescimento dos folículos antrais e alteração da proporção de folículos maiores ao estro 
(Driancourt \& Fry, 1992). Em ovelhas cíclicas quando aplicado após o progestágeno permite reduzir inclusive o intervalo ao estro quando comparado a fêmeas que recebem apenas a fonte de progesterona (Barrett et al., 2004).

Ainda, vários experimentos principalmente nas espécies bovina e caprina revelam que a reutilização do dispositivo auricular permite alcançar níveis satisfatórios de estro e prenhez, inclusive, em programas de superovulação proporcionando uma vantajosa relação entre o custo e benefício (Almeida et al., 2006; Sudano et al., 2011; Mellado \& Valdez, 1997). Sendo assim, o objetivo deste trabalho experimental foi o de avaliar o desempenho do implante auricular a base de Norgestomet de primeiro uso e previamente reutilizado na incidência de estro de borregas da raça Texel associado ao eCG e a um análogo de prostaglandina.

\section{Material e métodos}

$\mathrm{O}$ trabalho experimental foi realizado em uma propriedade criadora de ovinos do município do Irani (SC) de latitude $-27^{\circ} 01^{\prime} 29^{\prime}$ ', longitude $-51^{\circ}$ 54' 06' e altitude $1047 \mathrm{~m}$ no mês de novembro. Um total de 60 borregas (um ano de idade) da raça Texel após, terem a sua condição corporal (CC 3 a 4) e peso vivo $(50$ a $60 \mathrm{Kg}$ ) avaliados foram separadas em dois grupos experimentais, os grupos NorgN- (Norgestomet novo) (n 30), controle e NorgR- (Norgestomet reutilizado) (n 30) grupo experimental. Previamente ao início do trabalho os dispositivos auriculares (n 30) foram empregados na sincronização do estro da espécie bovina por período de nove dias, para se obterem os dispositivos de segundo uso.

As fêmeas do grupo NorgN (n 30) receberam no dia 0 (início do tratamento), a aplicação auricular do dispositivo de Norgestomet por seis dias. No sexto dia da retirada do dispositivo receberam uma dose de eCG (400 UI) e de um análogo de prostaglandina $(1 \mathrm{ml})$ pela via intramuscular (im). Entretanto, as fêmeas do grupo NorgR (n 30) diferenciaram-se apenas por receberem os dispositivos utilizados previamente. A dose de Norgestomet empregada em fêmeas dos dois grupos experimentais consistiu em um terço da dose empregada na sincronização da espécie bovina.

Após a retirada dos dispositivos (sexto dia) auriculares de progestágeno as fêmeas foram colocadas junto a reprodutores $(10 \%)$ com o seu peitoral pintado (tinta óleo) com a finalidade de detectar as fêmeas em estro (anca pintada) por um período de cinco dias (120h). Os reprodutores previamente tiveram a sua aptidão reprodutiva avaliada por meio de exame andrológico. O parâmetro avaliado no trabalho experimental foi o índice de manifestação estral das fêmeas tratadas logo após, o tratamento com progestágeno, sendo para a análise estatística aplicada o teste não paramétrico, de qui- quadrado ao nível de significância de $\mathrm{P}>0,05 \%$.

\section{Resultados e discussão}

Quanto à manifestação de estro observada nos dois grupos experimentais, $95 \%$ das fêmeas o manifestaram (57/60). Resultado este similar ao encontrado por Awel et al. (2009) quem utilizando metade da dose do Norgestomet recomendado para bovino obtiveram $87.5 \%$ das fêmeas em estro e Santos \& Barcelos (2012) quais empregando também, metade da dose e com seis dias de duração com o progestágeno obtiveram $100 \%$ das fêmeas em estro.

No que diz respeito aos grupos individualmente, no grupo NorgN $100 \%$ das fêmeas manifestaram estro (30/30) dentro das 36 $\mathrm{h}$ após, a retirada do dispositivo com progestágeno. No grupo NorgR entretanto, $90 \%$ delas o manifestaram (27/30) no mesmo período de tempo, não mostrando diferença significativa. Nesse respeito, Cardwell et al. (1998) observaram a manifestação de estro após 10 dias de Norgestomet com aplicação de eCG (500 UI) na retirada às $32 \mathrm{~h}$ dessa. Isto prova que os dispositivos reutilizados permitiram induzir de maneira eficiente a manifestação de estros. Além do mais, permitem serem reutilizados após serem empregados na indução e ou sincronização de estro bovino ou ovino. A Figura 1 apresenta a distribuição dos estros nos dois grupos.

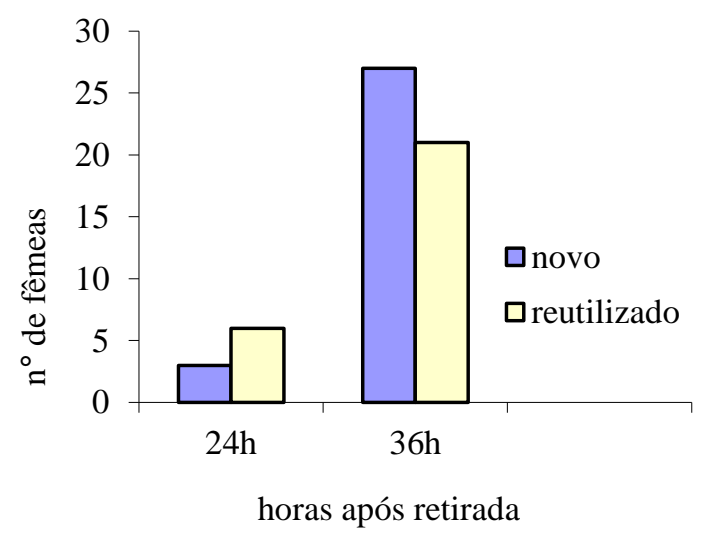

Figura 1. Manifestação de estro após a retirada do dispositivo auricular a base de Norgestomet nos grupos experimentais. 
Considerando o período de manifestação de estro nos grupos se pode observar uma maior manifestação dentro das $36 \mathrm{~h}$ da retirada do progestágeno, onde $80 \%$ (48/60) do total de fêmeas o manifestaram. Observando a manifestação estral em cada grupo, no grupo NorgN $90 \%$ das fêmeas estavam em estro nesse período (27/30) enquanto, no grupo NorgR 70\% delas o manifestaram não mostrando diferença significativa. A Tabela 1 reúne os dados de manifestação estral entre os grupos experimentais em percentagem. Quando se refere ao MAP como fonte exógena de progesterona os resultados mostram uma maior percentagem de fêmeas em estro no período das $48 \mathrm{~h}$ da retirada dos dispositivos (Zeleke et al., 2005).

Tabela 1. Manifestação de estro (número de animais) nos grupos NorgN e NorgR (percentagens) após retirada do dispositivo auricular a base de Norgestomet.

\begin{tabular}{lccccc}
\hline Grupos & Estro (hs) & Estro (hs) & Estro (hs) & Estro (hs) & Estro (hs) \\
\hline & 12 & 24 & 36 & 48 & 72 \\
NorgN (n 30) & 0 & $3 / 30(10 \%)^{\mathrm{a}}$ & $27 / 30(90 \%)^{\mathrm{a}}$ & 0 & 0 \\
NorgR (n 30) & 0 & $6 / 30(20 \%)^{\mathrm{a}}$ & $21 / 30(70 \%)^{\mathrm{a}}$ & 0 & 0 \\
\hline
\end{tabular}

*letras iguais refletem a não existência de diferença significativa entre grupos experimentais $(\mathrm{P}>0,05 \%)$.

Essa manifestação precoce de estro pode ser resultado da ação da gonadotrofina (eCG) a qual, permite um maior crescimento folicular e assim, a presença de folículos com capacidade ovulatória ao final do tratamento com progestágeno. Cardwell et al. (1998) em trabalho anteriormente citado, concluíram que o tempo de ovulação após a retirada do dispositivo de Norgestomet foi de $68.6 \mathrm{~h}$ o que permite também o emprego desse progestágeno em programa de inseminação a tempo fixo (IATF).

Cabe ressaltar que em relação à maneira de aplicação e índices de perda o dispositivo de uso auricular mostrou-se prático e seguro. Por se ter cuidado com a assepsia tanto na colocação como retirada do produto, não foram observadas quaisquer tipo de lesão na região da orelha nos animais tratados. Se faz necessário em próximos experimentos avaliar o desempenho em relação à índices de prenhez dos dispositivos a base de Norgestomet reutilizados.

\section{Conclusão}

Conclui-se que dispositivos auriculares a base de Norgestomet novos e reutilizados quando associado à eCG e a um análogo de prostaglandina permitem uma satisfatória manifestação estral em borregas da raça Texel.

\section{Referências bibliográficas}

Almeida, B. A. Bertan, C. M., Rosa, L. A. F., Gaspar, P. S., Binelli, M. \& Madureira, H. 2006. Avaliação da reutilização de implantes auriculares contendo norgestomet associados ao valerato ou ao benzoato de estradiol em vacas Nelore inseminadas em tempo fixo.
Brazilian Journal Veterinary Research Animal Science, 43(4), 456-465.

Awel, H., Eshetu, L., Tadesse, G., Birhanu, A. \& Khar, S. K. 2009. Estrus synchronization in sheep with synthetic progestagens. Tropic Animal Health Production, 41, 1521-1524.

Barrett, D. M. W., Bartlewski, P. M., BatistaArteaga, M., Symington, A. \& Rawlings, M. C. 2004. Ultrasound and endocrine evaluation of the ovarian response to a single dose of $500 \mathrm{UI}$ of eCG following a 12 day treatment with progestagen releasing intravaginal sponges in the breeding and non breeding seasons in ewes. Theriogenology,61, 311-327.

Cardwell, B. E., Fitch, G. Q. \& Geisert, R. D. 1998. Ultrasonic evaluation for the time of ovulation in ewes treated with norgestomet and norgestomet followed by pregnant mare's serum gonadotropin. Journal of Animal Science, 76, 2235-2238.

Driancourt, M. A \& Fry, R. C. 1992. Effect of superovulation with $\mathrm{pFSH}$ on growth and maturation of the ovulators follicles in sheep. Animal Reproduction Science, 27, 279-292.

Dutt, R. H. 1952. Induction of estrus and ovulation in anestrual ewes by use of progesterone and pregnant mare serum. Journal of Animal Science, 12, 515-523.

Farfán, J., Forero, J., Grajales, H. \& Eira, J. 2004. Effect of two different treatment with progestagens on heat synchronization in Colombian Creole sheep. Reproduction Fertility Development, 16(4), 506.

Godfrey, R. W., Collins, J. R., Hensley, E. L. \& Wheaton, J. E. 1999. Estrus synchronization 
and artificial insemination of hair sheep in the tropics. Theriogenology, 51, 985-997.

Gonçalves, P. B. D., Visintin, J. A., Oliveira, M. A. L., Montagner, M. M. \& Costa, L. F. S. 2002. In: Gonçalves, P. B. D., Figueiredo, J. R. \& Freitas, V. J. F. (Eds.). Biotécnicas aplicadas à reprodução animal (p. 195-196). Varelas, São Paulo, Brasil.

Hayatu, A., Lisanework, E., Gebrechiwot, T., Alemselam, B. \& Khar, S. K. 2009. Estrus synchronization in sheep with progestagens. Tropical Animal Health and Production, 41, 1521-1524.

Henderson, D. C., Downing, J. M., Beck, N. F. G. \& Lees, J. L. 1984. Oestrous synchronization in ewes a comparison of prostaglandin F2 $\alpha$ tham salt with a progestagen pessary. Animal Production, 39, 229-233.

Killen, I. D. \& Moore, N. W. 1970. The effect of pregnant mare serum gonadotropin and human chorionic gonadotropin on ovulation and fertility in the ewe. Australian Journal Agriculture Research, 21(5), 807-814.

Kinghts, M., Hoehn, T., Lewis, P. E. \& Inskeep, E. K. 2001. Effectiveness of intravaginal progesterone inserts and FSH for inducing synchronizes estrus and increasing lambing rate in anestrus ewes. Journal of Animal Science, 79,.1120-1131.

Mellado, M \& Valdéz, R. 1997. Synchronization of estrus in goats under range conditions treated with different doses of new or recycled norgestomet implants in two seasons. Small Ruminant Research, 25, 155-160.
Nagvi, S. M. K., Gulyani, R. \& Pareek, S. R. 1996. Estrus synchronization with progesterone impregnated vaginal sponges during summer season. Indian Journal Animal Reproduction, 7, 15-16.

Santos, F.C.C \& Barcelos, R.A.D. 2012. Eficiência de protocolos de sincronização de estro em ovelhas. Revista Brasileira de Reprodução Animal, 36, 3, 202-205.

Sudano, M. J., Alvarenga, F. C. L., Sartori, R. \& Machado, R. 2011. Reuse of norgestomet implants in an eCG-based superovulation protocol administered to Nelore (Bos Taurus indicus) cows. Livestock Science, 141, 207212.

Woody, C. O., Beauchene, S. L., Feccia, R. C., Sepe, P. A., Higgins, F. M., Cowan, W. A. \& Riesen, J. W. 1983. Regulation of the estrus cycle in ewes with progestin containing implants: influence of dose and day of cycle treatment. Theriogenology, 19, 677-684.

Zeleke, M., Greyling, J. P. C., Schwalbach, L. M. J., Muller, T. \& Erasmus, J. A. 2005. Effects of progestagen and PMSG on oestrus synchronization and fertility in Dorper ewes during the transition period. Small Ruminant Research, 56, 47-53.

Recebido: 5 Jun. 2018.

Aprovado: 14 Jun. 2018

Publicado: 9 Jul. 2018

Licenciamento: Este artigo é publicado na modalidade Acesso Aberto sob a licença Creative Commons Atribuição 4.0 (CC-BY 4.0), a qual permite uso irrestrito, distribuição, reprodução em qualquer meio, desde que o autor e a fonte sejam devidamente creditados 